\title{
What Do We Know about Legal Empowerment? Mapping the Evidence
}

\author{
Laura Goodwin' ${ }^{1}$ Vivek Maru'
}

Published online: 7 February 2017

(C) The Author(s) 2017. This article is published with open access at Springerlink.com

\begin{abstract}
World governments have embraced 'legal empowerment' as an end in itself and as an essential element in the fight against poverty. Civil society groups work to advance legal empowerment around the globe but, to date, there is not a comprehensive understanding of the impact of those efforts. This article offers the first review and mapping of existing evidence on legal empowerment. We identified and analyzed 199 studies in total. These studies span every major continent and address a wide range of legal empowerment interventions, such as legal literacy, community-based paralegals, and use of right to information laws. The breadth and richness of this body of work suggest we should revisit previous perceptions that there is little evidence on what legal empowerment can achieve. Stronger agencyboth people's willingness to act and actual action-as well as increased legal knowledge are the most common positive impacts reported in this collection of evidence. The evidence also suggests legal empowerment programs can lead to acquisition of legal remedies, effective conflict resolution, and even improvements
\end{abstract}

This effort has benefitted from many contributors. In particular, we would like to thank Gregory Barrett, Daniel Brinks, Varun Gauri, John Gaventa, Bilal Siddiqi, and Michael Woolcock for their guidance in defining the scope and methodology of this review. We express our deep gratitude to Hazim Al-Eryani, Srinivas Ayyagari, Denise Bell, Luciana Debenedetti, Beth Goldberg, David Kienzler, Amarachi Utah, Allison Vuillaume for their invaluable assistance with researching, reviewing, and/or coding studies. Big thanks to Akhila Kolisetty, and Karima Tawfik for additional research assistance. We are also extremely appreciative of those who commented on an earlier draft of this article, including Emily Brown, Marco de Swart, Adrian Di Giovanni, Pilar Domingo, William Evans, Tamar Ezer, Macha Farrant, Suella Fernandes, Martin Gramatikov, Shelley Inglis, Ralf Jurgens, Monjurul Kabir, Zaza Namoradze, Joss Saunders, Lotta Teale, Lars Waldorf, Meghan Watkinson, and others who helped shape the original scope of inquiry, recommended additional pieces of impact evidence for this review, or provided other advice along the way.

Laura Goodwin

lauragoodwin@namati.org

1 Washington, USA 
in health and education outcomes. Nearly ninety studies find positive impacts of legal empowerment programs on institutions - changes in law, policy or practice at various levels of administration. After exploring distributions and trends in the evidence, the article concludes by identifying gaps and questions for further inquiry to guide future research and, ultimately, promote stronger, more evidence-based practice.

Keywords Justice · Legal Empowerment · Evidence · Human Rights

\section{Introduction}

The United Nations Commission on Legal Empowerment estimated that 4 billion people live outside the protection of the law. ${ }^{1}$ For these people the law is an abstraction, or a threat, but not something they can use to exercise their basic rights.

'Legal empowerment' is about reversing that trend: about giving people the power to understand and use the law. A farmers' association in Cambodia deploys community paralegals to support its members in protecting their land rights. Advocates in Jordan assist migrant workers to recover salaries and passports unlawfully withheld by employers. A public interest law organization in Argentina helps slum dwellers to demand clean water.

The legal empowerment movement grows out of the legal aid tradition, which in turn is nearly as old as law itself. ${ }^{2}$ Stephen Golub coined the phrase 'legal empowerment' in 2003, and since then it has been used to refer to efforts which:

1. Focus on the direct capacity of citizens to exercise their rights (in contrast, conventional legal aid is sometimes construed as an expert service, with less attention to the agency of the beneficiaries), and

2. Engage a wide range of institutions, including customary tribunals and administrative agencies, marking a sharp distinction to the narrow focus on the judiciary in much of the rule of law sector. ${ }^{3}$

In 2008, the United Nations convened the High Level Commission on Legal Empowerment of the Poor. The Commission, whose members included Madeline Albright, Gordon Brown, Ernesto Zedillo, and Fernando Cardoso, called for integration of legal empowerment into the global fight against poverty. The

\footnotetext{
1 Commission on Legal Empowerment of the Poor (2017).

2 In the Roman Empire under early Christian rulers, the Council of Chalcedon decreed in $451 \mathrm{AD}$ that the clergy should provide assistance, including legal aid, for widows, orphans, and those who lacked the means to procure counsel on their own. Judges in church courts—and the Pope himself-appointed advocates to argue without fees on behalf of poor and disadvantaged litigants as early as the twelfth century. Brundage (2008), at pp. 35, 190-191. England's first legal aid law was the enactment of the forma pauperis procedure in 1495, which provided for the appointment of free counsel for the indigent. Mahoney (1998), pp. 223, 223-240. Legal aid efforts in the United States trace back to the nation's founding, including the New York Manumission Society, which provided free legal services to fugitive slaves and free black people from 1790 to the 1830s. Harris (2004), p. 208.

3 See generally Golub 2003a. See also Maru (2010b).
} 
Commission defined legal empowerment as 'a process of systemic change through which the poor and excluded become able to use the law, the legal system, and legal services to protect and advance their rights as citizens and economic actors' ${ }^{4}$ With this focus, the Commission emphasized property rights, labor rights, and business rights in addition to the foundation of access to justice and the rule of law. Goal 16 of the Sustainable Development Goals, adopted by the United Nations General Assembly in September 2015, states 'Promote peaceful and inclusive societies for sustainable development, provide access to justice for all and build effective, accountable and inclusive institutions at all levels. ${ }^{5}$ This is a significant departure from the original Millennium Development Goals, which did not address issues of law or justice at all. ${ }^{6}$

Despite this growing prominence, however, and many examples of success, there is no comprehensive understanding of what legal empowerment programs have achieved. Nor is there a framework to guide future research based on identified gaps in our existing knowledge. Understanding what works, where, and why can underpin evidence-based decision making and the effectiveness of these strategies as the field expands. ${ }^{7}$

We offer here a review - the first of its kind - of all available evidence on civil society-led legal empowerment efforts. This is the first review to pull together evaluations and other assessments of programs around the globe and to use a coding methodology to map trends in the research. In this review we do not attempt to assess the rigor of the studies, but rather we take the results at face value in order to look at patterns across the existing body of evidence on legal empowerment. ${ }^{8}$

We begin the article by describing our methodology. We then offer initial snapshots of the evidence we collected, in particular the distribution across regions and across evaluation methods. Before turning to analysis, we highlight two key limitations - the difficulty in determining whether patterns reflect legal empowerment work or only research priorities and the influence of positive publication bias-that make it difficult to draw conclusions despite the rich body of existing material. Those caveats notwithstanding, we offer insights in six broad areas: legal empowerment strategies; resulting impacts; the kinds of problems legal empowerment has addressed; the institutions engaged in the process; the political regimes in which these programs take place; and scale. We conclude by identifying gaps in existing research and key substantive questions that merit further inquiry.

\footnotetext{
4 See generally Commission on Legal Empowerment of the Poor, Making the law work for everyone, supra n. 1.

5 UN Secretary-General 2014.

6 See, for example, James Goldston, 'UN Meeting on the Rule of Law Was Just Another Day of Talk', The Guardian, 26 September 2012 (calling on the United Nations to incorporate issues of law and justice into the new round of global development goals).

7 Golub 2010 (discussing the need for more research into the impact of legal empowerment initiatives). See also Wojkowska and Cunningham 2010, pp. 93, 108; Domingo and O'Neil (2014), pp. 13-17.

8 This paper builds on earlier reviews, such as a 2001 study of the effects of legal empowerment on governance and poverty reduction, Golub and McQuay (2001).
} 


\section{Methodology}

\subsection{Definitions and Scope}

For the purpose of this review, we defined civil society legal empowerment efforts as those that seek to increase the capacity of people to understand and use the law. ${ }^{9}$ We interpret 'law' broadly, to mean not just legislation but also regulations and policy.

This definition of legal empowerment covers a diverse range of organizations and strategies. It includes efforts to support people in pursuing a remedy to a breach of individual liberty. It also includes, for example, interventions that enable people to monitor the extent to which local service delivery institutions like health clinics and schools comply with the laws or policies that govern them. ${ }^{10}$ After discussion with several experts we concluded that, despite this breadth, the common goals uniting this body of work would allow for meaningful comparative analysis.

In identifying studies to include in the review, we looked for interventions with a 'process' component. Legal empowerment strategies focus on not only a just outcome, but also, crucially, on the ability of people to engage in law-related processes. ${ }^{11}$ An advocacy campaign to pass a law against gender-based violence, for example, might well lead to greater protection of women's rights. We would not include an evaluation of it, however, unless the advocacy effort had an explicit focus on increasing people's participation in the lawmaking process.

Similarly, we excluded most studies examining public interest litigation, even though those lawsuits often took on crucial human rights issues. In the few examples we did include, the organizations involved did not treat clients as victims requiring the help of technical experts. Rather, the organizations made a concerted effort to build the ability of its clients to understand, and ultimately drive, the process of litigation.

The review focuses on work by civil society organizations. We did consider studies of two quasi-state institutions - human rights commissions and ombudsman offices-because of the distinctive role those institutions play in serving as advocates for the general public. As with public interest litigation and issue-based advocacy, we only included studies of human rights commissions or ombudsman offices if the efforts by those institutions sought to increase the capacity of citizens to exercise their own rights.

We adopted an expansive definition of 'evidence.' We included any documents that addressed impact or changes resulting from a legal empowerment intervention, including data based on randomized control trials, quantitative survey research, qualitative interviews, focus group discussions, participatory techniques, and case

\footnotetext{
9 See Golub (2003a), pp. 10-11.

${ }^{10}$ Such initiatives are sometimes described as advancing 'social accountability'. Though one of us has previously described 'legal empowerment' and 'social accountability' as distinct, complementary traditions, see Maru (2010b), pp. 83, 83, we included 'social accountability' interventions in this review whenever they met our definition of legal empowerment.

11 See Golub (2003a), pp. 10-11. See also Domingo and O'Neil (2014), pp. 13-14.
} 
studies. These documents appeared in a range of locations, including peer-reviewed journals, grey literature from donor agencies and implementing organizations, and self-standing program evaluations.

Each data collection method has its own strengths in generating knowledge about legal empowerment. While some view randomized control trials as ideal, in our view, such experiments are neither possible nor desirable in all cases. ${ }^{12}$ Case studies and open-ended qualitative interview questions may better capture the complexity of context and how interventions affect people's daily lives. Participatory methods are specifically intended to incorporate the insight of the ultimate constituents of legal empowerment programs. Overall, mixed methods and triangulation of results from different sources may provide a better basis of knowledge than any one data collection method alone.

As the following section explains, this review is based on a quantitative mapping of the available evidence, using coding. We intend to write a future paper that will analyze the evidence in a more qualitative way, comparing in more detail the findings of particular studies.

\subsection{Research Steps}

The research team used five strategies to find and compile legal empowerment evidence: examination of existing literature reviews, general online searches, searches on the websites of major institutions supporting legal empowerment, a targeted 'call for evidence', and interviews with experts in the field. The aim of the research methodology was to collect as much existing evidence as possible within a limited timeframe.

There are no existing comprehensive reviews on the impact of legal empowerment. However, there are several major studies ${ }^{13}$ that compile impact evidence on topics within or closely related to this field. In order to build on this foundation of knowledge, our research effort started by collecting impact evidence within the content and citations of these related literature reviews.

The second research strategy involved internet searches. The search process had three components. The first step was research on Google Scholar, which mainly returned academic and other peer-reviewed studies. The second step was the use of the same search terms within Google's general search function. The results included both academic works as well as a variety of grey literature and program evaluations from donors, multilateral institutions, and civil society organizations. The third step followed relevant citations in already compiled studies until we felt the leads were largely exhausted.

Third, similar searches targeted the websites of institutions that implement, support, or research legal empowerment programs. These organizations include the

\footnotetext{
12 See generally Pritchett and Sandefur (2014) and Ravallion (2009).

13 See Department for International Development, Research and Evidence Division, 'A Preliminary Mapping of the Evidence Base for Empowerment and Accountability’ (2010), available at http://r4d.dfid. gov.uk/PDF/Publications/FINAL_E_and-A_Annex3_Evidence_Mapping.pdf; Maru (2010a); Dena Ringold et al. (2012); Commission on Legal Empowerment of the Poor, see n. 1, Working Group Reports, Chapters 1-4, (2008); Deininger and Feder 2009, p. 233; Gaventa and Barrett 2012; World Bank (2011).
} 
Abdul Latif Jameel Poverty Action Lab (J-PAL), the United Nations Development Programme (UNDP), the World Bank Justice for the Poor Program (J4P), the UK Department for International Development (DFID), and the International Development Law Organization (IDLO), among many others.

Our organization, Namati, convenes a global network on legal empowerment that includes practitioners from every region of the world. One of the key reasons for building the network is to promote knowledge sharing and evidence-based decision making. Our fourth research strategy was a 'call for evidence' to the network, through which we hoped to identify program evaluations and other studies not readily available on the internet. At the time, there were approximately 135 legal empowerment organizations and 700 individuals represented on the network. Several network members contributed evaluations of their work. During peer review of an early draft of this article, legal empowerment practitioners and donor agencies recommended additional studies, over 60 of which fit the project's scope and definitions.

Finally, interviews with specific individuals known for their expertise in this field led to recommendations about specific pieces of evidence as well as refinement of the scope and methodology of this study. ${ }^{14}$

After several months ${ }^{15}$ of reviewing literature and gathering evidence, the research team had complied 199 pieces of evidence on the impact of legal empowerment. ${ }^{16}$

\footnotetext{
${ }^{14}$ The experts included: Dr. Daniel Brinks, Associate Professor and Co-Director of Bernard and Audre Rapoport Center for Human Rights and Justice, University of Texas at Austin School of Law; Dr. Varun Gauri, Senior Economist, Development Research Group, The World Bank; Dr. John Gaventa, Director, Coady International Institute and Vice President, International Development at St Francis Xavier University; Bilal Siddiqi, PhD., Minerva Postdoctoral Fellow, Center on Democracy, Development, and the Rule of Law, Freeman Spogli Institute for International Studies, Stanford University; and Dr. Michael Woolcock, Lead Social Development Specialist, Development Research Group, The World Bank.

15 The research team concluded the search process in early 2013 in order to move to coding. Evaluations and other types of evidence published after that time are not included in this review. Subsequent studies not incorporated into this review include Ramanujam and Anstis (2013) (using Cambodia as a case study to show links between legal empowerment and equitable economic growth); Kurze et al. (2015), p. 260 (examining use and impact of legal empowerment with reference to transitional justice through a series of case studies).

${ }^{16}$ For studies that covered more than one legal empowerment intervention-whether across several countries or multiple distinct efforts in one nation - the impacts of each intervention are coded separately. Only six pieces of evidence in this review are exceptions - the six studies coded as 'multiple countries'. Three of these pieces of evidence are meta-analyses, from which we did pull out and code any legal empowerment studies separately. We also coded those larger articles in order to incorporate their unique findings as well. Two other studies drew from 121 evaluations related to community governance of water projects. While the bibliography was available, coding each of those 121 studies individually would have greatly skewed the results of this review while failing to take advantage of the overarching analysis already completed in those works. The last study was a book-length piece for which it was difficult to separate out each case and its impacts for coding. We acknowledge that some studies cover interventions of limited size or duration, while others may review the impact of a sustained, national-level program. We made the decision that attempting to weight studies may not increase the accuracy of our findings, and thus we count each piece of evidence equally in our analysis. For an Appendix of all sources reviewed, see Appendix 3: List of Studies, Namati, http://namati.org/wp-content/uploads/2015/02/Appendix-3-Listof-Studies-Reviewed.xlsx.
} 
Table 1 Impact types

\begin{tabular}{lc}
\hline Citizens and consciousness & Institutional \\
\hline Rights consciousness & Change in law or policy \\
Legal knowledge & National \\
Agency and participation & Provincial/state \\
$\quad$ Willingness to act & Local \\
$\quad$ Actual action or participation & Change in implementation or practice \\
Acquire remedy, entitlement, info & National \\
Conflict resolution/Case resolution & Provincial/state \\
Sense of fair process & Local \\
Status change & \\
Social inclusion & \\
Development outcome & \\
$\quad$ Health & \\
Education & \\
Income &
\end{tabular}

\subsection{Coding and Analysis}

In order to detect patterns in such a large pool of evidence, we coded each study by several different factors ${ }^{17}$ :

1. Type of impact (e.g., legal knowledge; health outcomes);

2. Nature of impact (positive; negative; null/none);

3. Issue area (e.g., family dispute; economic injustice; children's rights);

4. Legal empowerment approach (e.g., paralegals; legal literacy; RTI);

5. Institutions engaged (e.g., regulatory agency; police; media);

6. Political regime type (free; partly free; not free);

7. Scale of intervention (e.g., 1000 to 10,000 people);

8. Evaluation method (e.g., focus groups; survey).

Creating the typology for type of impact was an iterative process. We divided impacts into two large categories. (See Table 1) The first is changes that affect individuals and communities. These range from increases in people's knowledge of the law and greater action in pursuit of rights to success in obtaining legal remedies and improvements in overall well-being.

Some interventions create positive impact on not just individuals or groups of people, but on public institutions. Institutional impact might result directly from individual attempts to seek redress. For example, community paralegals teach slum dwellers how to file right to information requests to demand explanations for interruptions in water supply. Faced with the possibility that corruption or incompetence would be disclosed, officials in the municipal water authority find a

\footnotetext{
${ }^{17}$ For the full coding guide, see Appendix 1: Coding Guide, Namati, http://namati.org/wp-content/ uploads/2015/02/Appendix-1-Coding-Guide.pdf.
} 
way to fix the pipeline. According to our codes, this is a change in local institutional practice.

In other cases, individual attempts to seek redress run into structural problems, and organizations pursue institutional change to address those problems. A rural women's group supports its members to register their property rights, say, but applications stall because the government has not deployed staff in the local land administration office. If the women's group then mobilized its members to successfully advocate for an increased budgetary allocation to local land administration, we would code that result as a change in national policy.

The evidence reflects not a single theory of change but rather many causal pathways. Unintended consequences are also possible. A community paralegal program that obtains concrete remedies for women who have been abused might actually provoke a backlash and thereby decrease 'social inclusion'. But together, these various codes reflect the range of outcomes that legal empowerment efforts seek to achieve.

The research team deferred to the framing of results by each study's author(s) to code for the nature of impacts (positive, negative, or null/none). The code for 'null' impact was applied only when a study sought to measure the impact in question, but found no change. Codes were applied per impact type and captured the fact that a single intervention could have both positive and negative effects, or could have accomplished some intended objectives while failing to catalyze change in others.

To differentiate between political regimes in each country of intervention, the research team adopted Freedom House's Freedom in the World 2012 rankings. ${ }^{18}$ Although all rankings of this nature are imperfect, the Freedom House index had several advantages from the perspective of a review on legal empowerment around the globe. First, Freedom House ranks 195 countries and 14 territories, making Freedom in the World one of the most comprehensive governance-related indices. Second, Freedom House examines the strength of political rights and civil liberties as experienced by individuals-more relevant to legal empowerment interventions than a purely de jure analysis. Third, for each country there is a final ranking of 'free', 'partly free', or 'not free'. These labels clearly designate the boundary of each category for ease of coding.

The research team applied a code for the scale of each intervention. We coded for the number of people covered by the program: 0 to $1000 ; 1000$ to 10,$000 ; 10,000$ to 100,$000 ; 100,000$ to 1 million, and over 1 million people. The researchers marked studies that did not specify program size as 'unknown scale'.

After the coding was complete, we analyzed the data in Excel and STATA to uncover patterns, relationships among variables, and research gaps.

\footnotetext{
18 See Freedom House (2015) for detailed information on the rankings and methodology used by Freedom House. For multi-intervention studies in which impacts were not broken out by country, the study was coded 'various countries' and did not receive a political regime designation.
} 


\section{Snapshots of the Evidence}

There is substantial evidence on the impact of legal empowerment interventions The research team identified 199 studies that address the results of a wide range of legal empowerment work. The breadth and richness of this body of work suggest we should revisit previous perceptions that there is little evidence on what can be achieved through legal empowerment or that there are few methodologies available for such measurement. ${ }^{19}$ The studies collected here not only provide a basis for understanding the accomplishments of prior work, but also can inform the design and implementation of legal empowerment initiatives going forward. This information can promote evidence-based decision making and ultimately more effective interventions.

In the course of conducting this review, the research team also came across several legal empowerment studies that were underway at the time. The evidence base will continue to grow as this work is completed, published, and shared.

\subsection{Regional Distribution}

The evidence covers interventions on every major continent. (See Fig. 1) Asia is the most represented, home to nearly $40 \%$ of the studies in the review. Interventions in Africa made up over one-third of the total, followed by North America, South America, and Europe. There is a striking gap in knowledge about legal empowerment in the Middle East. Despite research in Arabic and outreach to regionally active legal empowerment organizations, we found only one study covering an intervention in the region.

The regional distribution of evidence may be due in part to the research team conducting the majority of searching in English, supplemented by consultants using an abbreviated research protocol in Arabic, French, and Spanish. The full research methods described above could be replicated in additional languages to uncover evidence on legal empowerment beyond what is represented in this article.

India and Bangladesh are the two countries most represented in this collection of evidence, with 24 and 18 studies respectively. (See Table 2) Legal empowerment interventions in Indonesia and Uganda are also relatively well-studied.

\subsection{Evaluation Methods}

A wide range of data collection methods have been used to measure the impacts of legal empowerment. (See Fig. 2) Many studies used multiple data collection methods to capture impact.

Case studies and interviews are the most common data collection methods, followed by quantitative surveys. This distribution suggests that the legal empowerment field values both quantitative and qualitative evaluation methods.

\footnotetext{
19 For example, 'Just as the top-down approaches to justice sector reform are built on limited evidence of success (as detailed to such effect by Carothers), empirical evidence to convince policy-makers that legal empowerment works is admittedly equally thin on the ground.' Stephens 2009, pp. 132, 140.
} 


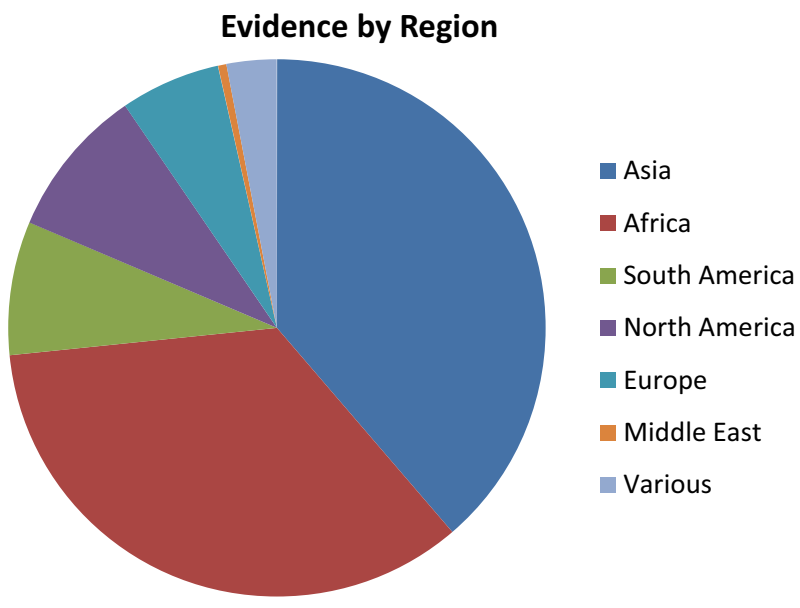

Fig. 1 Evidence by Region

Table 2 Evidence distribution by country
Evidence distribution (number of studies) by country

\begin{tabular}{lll}
\hline Afghanistan 1 & Ghana 4 & Peru 1 \\
Angola 1 & Guatemala 1 & Philippines 8 \\
Argentina 3 & Honduras 1 & Rwanda 1 \\
Bangladesh 18 & India 24 & Senegal 2 \\
Belgium 1 & Indonesia 14 & Sierra Leone 4 \\
Benin 1 & Japan 1 & Somalia 1 \\
Bolivia 3 & Kenya 7 & South Africa 8 \\
Brazil 1 & Liberia 5 & South Sudan 1 \\
Burma 1 & Madagascar 1 & Tanzania 6 \\
Burundi 1 & Malawi 5 & Thailand 2 \\
Canada 1 & Mexico 9 & Uganda 12 \\
Colombia 1 & Morocco 1 & Ukraine 1 \\
DRC 2 & Mozambique 4 & United Kingdom 8 \\
East Timor 1 & Nepal 2 & United States 8 \\
Ecuador 3 & The Netherlands 1 & Yemen 1 \\
El Salvador 2 & Pakistan 2 & Zambia 1 \\
Georgia 1 & Papua New Guinea 3 & Zimbabwe 1 \\
& & Multiple 6 \\
\hline & & \\
\hline
\end{tabular}

There was one striking omission: based on our review, participatory evaluation methods are rarely used in studies of legal empowerment interventions. Participatory evaluation strives to include the ideas, opinions, and values of people affected 


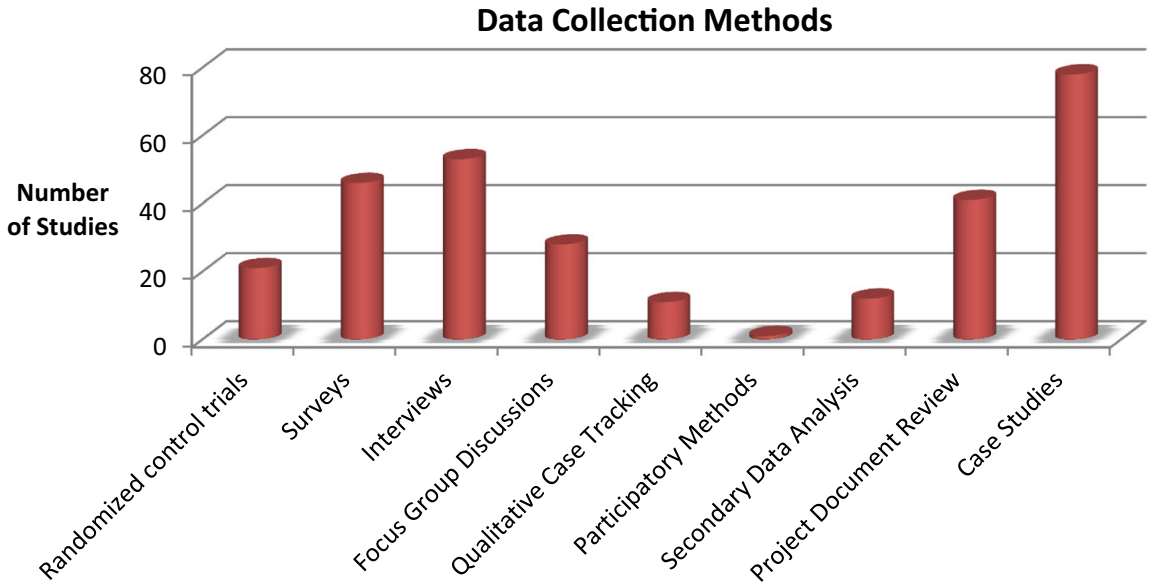

Fig. 2 Data collection methods

by an intervention throughout the entire process - from the design of the evaluation questions, to the data collection, analysis, reporting, and follow-up response. ${ }^{20}$ Participatory evaluation can be an intervention in itself-an opportunity to increase people's participation and agency.

Community mapping, for example, is a participatory approach with potential application to legal empowerment evaluations. The monograph 'Protecting Community Lands and Resources: Evidence from Liberia, Mozambique, and Uganda' describes community mapping, in which groups of women, youth, and elders each drew a map labeling all borders, landmarks, roads, schools, clinics, religious sites, and the locations of natural resources in their area. ${ }^{21}$ The community mapping was one step in the process to secure a community land title, rather than an evaluation method-the study, which was designed as a randomized field experiment, utilized pre and post-service surveys, focus group discussions, and field team observations to explore the effects of the intervention.

However, the information gained from the mapping shows the value of such participatory methods. The mapping exercise not only led to a visual display of the community's assets, but also provided insight into gender roles and their relation to resource management. For example, the women mapped more comprehensively than the men. The men left out many resources vital to women's livelihoods, such as water sources. Traditional monitoring and evaluation methods may have missed these dimensions of community life and led to uninformed decisions related to resource rights.

Overall, the legal empowerment field might more frequently design evaluation studies in a way that speaks to the same principles as those of the

\footnotetext{
${ }^{20}$ For more information on participatory evaluation, see Irene Guijt and John Gaventa, 'Participatory Monitoring and Evaluation: Learning From Change', 12 IDS Policy Briefing (1998), available at http:// www.ids.ac.uk/index.cfm?objectid=01D512C5-5056-8171-7BA528050E140ED9.

21 Knight et al. (2012).
} 
interventions themselves-building people's capacity to engage in processes that affect them.

\section{Limits on Analysis}

\subsection{The Gap between Research and Practice and the Trouble with Too Much Good News}

Despite this rich body of evidence on legal empowerment, it is difficult to determine what works in which contexts based on existing information.

First, where patterns do exist, it is unclear whether they reflect the distribution of research or the nature of legal empowerment work itself. For example, of all interventions that had a positive impact on the policy or practice of institutions, the most frequent legal empowerment strategy was the use of advocacy, with studies of 53 programs citing instances of institutional impact. Other frequent strategies to show impact on institutions were community mobilization (39 studies) and community monitoring (32 studies).

Those figures do not necessarily support the conclusion that those particular strategies are more effective at achieving institutional change than approaches such as use of right to information laws or legal aid, which had 12 and 13 instances of impact on institutions respectively.

The contrast could be due to differing research priorities. Not only are some intervention strategies more represented in existing evidence, but researchers may also have a bias toward measuring certain impacts. Perhaps those who studied advocacy were more interested in measuring institutional change, while studies conducted on legal aid programs aimed to instead capture impacts on knowledge, agency, or social inclusion. Some of the numerical findings from this review may therefore reflect the distribution of existing evidence more than overall trends in legal empowerment or probabilities of achieving certain types of change.

To bridge the gap between the universe of actual legal empowerment work in the world and the scope of existing evidence on these interventions, we propose tracking the activities of Global Legal Empowerment Network members by the same categories used in this study-approach, issue area, region, type of impact, and so on. If we assume the network is representative of all legal empowerment work conducted globally_admittedly a leap-this data would help researchers identify areas in which legal empowerment practice outpaces examination.

Second, our review suggests a tendency to share positive results. We discovered very few instances of negative impact. Ninety-seven percent of the studies reported at least one positive change. In contrast, merely nine studies $(4.5 \%)$ identified any negative change that occurred during the course of the intervention. Forty-nine studies, or $25 \%$ of the total, reported a null impact. Most of these studies reported that the legal empowerment interventions had positive impacts in other areas.

There is often as much, if not more, to learn from efforts that result in unexpected or counterintuitive outcomes. A critical examination of 'failed' interventions or other factors that may contribute to a specific result provides an opportunity to 
reassess assumptions about context and theories of change, to improve the relevance of programming, and to inform future research priorities.

In addition, data about shortcomings can serve as comparative evidence against which positive results of similar interventions can be analyzed for a more robust understanding of 'what works, where, and why.' There is pressure from within organizations and from external parties to demonstrate program success and efficient use of resources - and for good reasons. However, we should not let these considerations discourage the honest, critical reflection needed for deeper learning and genuine evidence-based decision making. ${ }^{22}$

With those caveats, however, this review does yield a number of useful insights about legal empowerment. We organize our analysis below into six broad areas: strategies; impact; issues; institutions engaged; regime type in the country of interventions; and scale.

\section{Legal Empowerment Approaches}

Evidence on a wide range of legal empowerment approaches exists, though the data is more abundant for certain strategies. The most frequently studied legal empowerment approach in our review is legal literacy, which appears in 113 of the 199 interventions.

The evidence suggests that legal literacy strategies can produce a range of impacts. In one evaluation, Pandey, Goyal, and Sundararaman used a randomized control trial design to examine links between legal information campaigns and school performance. ${ }^{23}$ In three states, the intervention randomly allocated the delivery of legal education to a sub-set of $610 \mathrm{~g}$ panchayats (the smallest unit of local government). In treatment gram panchayats, a short film, posters, and wall paintings informed community members about the roles and responsibilities of village education committees, right to information and complaint procedures, and the benefits to which students are entitled, such as uniforms, textbooks, and meals. No information dissemination took place in the control gram panchayats.

The authors found a higher percentage of parents talking to teachers or the school oversight committee about school quality in the treatment gram panchayats. The delivery of resources also improved. Students in Madhya Pradesh and Uttar Pradesh were more likely to receive their cash stipends and uniforms after the intervention, compared to the baseline survey, and the quality of mid-day meals improved in Karnataka. However, the impact varied by caste. According to the study, the legal literacy intervention also had some effects on educational outcomes-reading, writing, and math scores improved in at least one state.

\footnotetext{
22 Thornton and Lee (2000), pp. 207-209. Song, Hooper and Loke (2013), pp. 71-73. Franco et al. (2014), pp. 1502-1504. Kremer (2003), pp. 102, 104-105 (mentioning the possibility of publication bias in randomized control trials of development interventions). Roselyn et al. (2012), pp. 1, 5 (discussing reluctance among NGOs to publish negative results regarding performance). See also van Rooij (2012), pp. 286, 308-309 (describing the trend towards presenting the results of impact studies of legal empowerment interventions as positive).

23 Pandey et al. (2009), p. 355.
} 


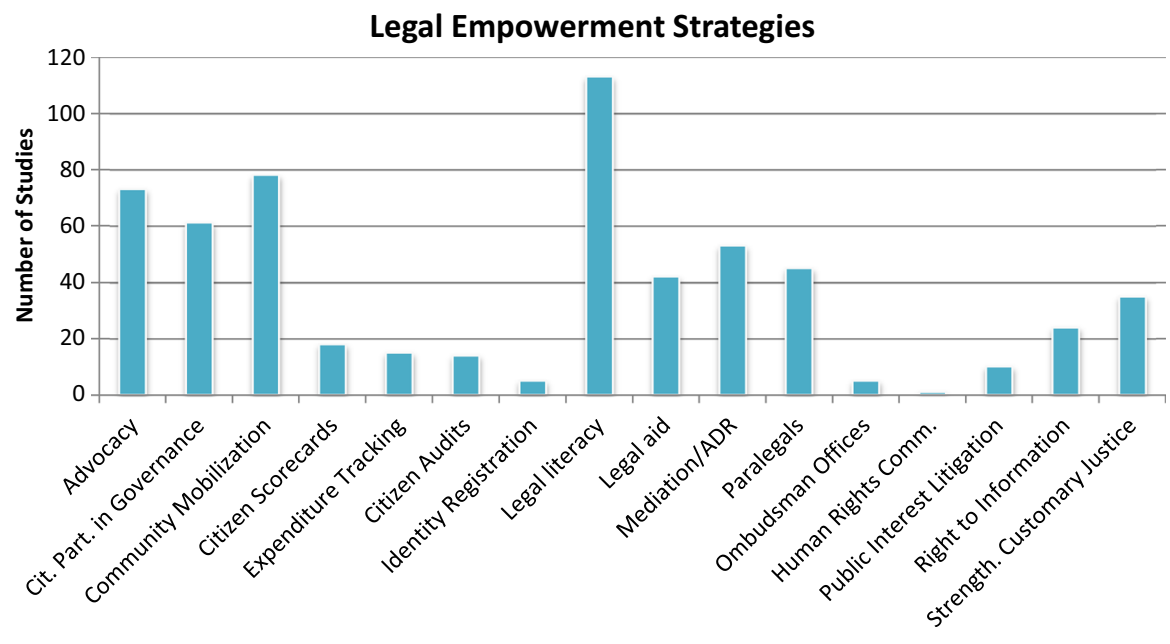

Fig. 3 Legal empowerment strategies

After legal literacy, the next two most common approaches are community mobilization and advocacy, which appeared in 78 and 73 studies respectively. (See Fig. 3) Mediation/alternative dispute resolution interventions were also well represented in the evidence.

Most interventions-175 out of 199-involved more than one legal empowerment approach. The median number of approaches per intervention was 3. These numbers are due in part to the nature of the strategy categories. Some categories refer to actors (paralegals, ombudsman offices), each of whom employ other approaches within our list. For example, in Ecuador paralegals adopted mediation/ ADR as a strategy within a program focused on protecting natural resources. ${ }^{24}$ In general, however one chooses to classify the various efforts, organizations pursuing legal empowerment tend to combine multiple strategies. In Zimbabwe, legal literacy built the capacity of women to monitor national budgets and to use their findings during advocacy for more equitable government allocations. ${ }^{25}$ An effort to promote women's rights in Papua New Guinea involved both mediation/ADR and legal education. ${ }^{26}$ Legal empowerment interventions also often combine community mobilization, advocacy, and use of right to information laws as complementary strategies.

The legal empowerment field has applied community monitoring strategies in a breadth of interventions. Citizen scorecards, expenditure tracking, and social audits all belong to the broader category of community monitoring. A total of 49 studies evaluated community monitoring interventions that provided people opportunities to assert their rights through enforcing government obligations (such as in service

\footnotetext{
${ }^{24}$ Glick et al. (1994).

25 Libert Muchabaiwa (2010), pp. 109, 126-128.

26 Johnstone (2011), pp. 15, 22-24.
} 
delivery) and/or to make decisions related to budgets, resource use, or other governance issues.

A case study on the Uganda Debt Network (UDN), for example, describes how the organization created monitoring committees at the village, sub-county, and district level. ${ }^{27}$ In these committees, people learned to monitor Poverty Action Fund (PAF) expenditures and check the performance of local government in service delivery. Ongoing communication between these entities culminated in annual 'district dialogues' at which community monitors present their findings to district authorities and demand concrete responses. These local committees exposed cases of poor quality work by contractors constructing schools or health clinics. The monitors also reported missing items or funds related to local service delivery. Where district officials were open to feedback, responses to these reports included investigations and recovery of materials such as school roofs, health clinic mattresses, and bicycles.

UDN works to bring these grassroots experiences to the national policy arena. After a community monitoring committee reported misuse of funds intended for school facility improvements in one district, UDN pushed for a national investigation. The government dealt with the misuse and then revised the national guidelines to strengthen accountability in the School Facilities Grant program. Some of the factors of success cited by the case study include UDN's strategic use of the media, the production of educational materials that 'demystify' budgets, carefully selected activities at each stage of the budget cycle, and strategic links within and outside of government.

Community monitoring programs, like most legal empowerment approaches, often include other complementary strategies. In Uganda, another program used newspapers to conduct a legal information campaign alongside efforts to increase parents' monitoring of education spending at the local level. ${ }^{28}$ An education-related intervention in Kenya, described below, not only established a system for community monitoring of teacher performance, but also directly empowered parents to govern the school through a management committee that could hire and fire teachers. ${ }^{29}$ Some programs combined public monitoring of government obligations with strategies that fall outside the realm of legal empowerment-one randomized control trial in India added top-down financial incentives to a community monitoring experiment to improve teacher attendance. ${ }^{30}$

Some evidence suggests that beyond combining legal empowerment strategies, pairing different justice service providers can also be an important element for success. A research project in Tanzania and Mozambique assessed the impact of legal empowerment interventions on the rural women most likely to experience gender discrimination related to land-divorced women and widows. ${ }^{31}$ The research team administered surveys to these women and local leaders in three types of

\footnotetext{
27 De Renzio et al. (2006).

${ }^{28}$ Reinikka and Svensson 2005, pp. 259, 260.

29 Duflo et al. (2007).

30 Duflo et al. (2010), pp. 1241, 1242-1243.

31 Kapur (2011), pp. 73, 82-87.
} 
communities: villages with active paralegals trained in land law and dispute resolution; villages with offices in which paralegals with similar training worked under the close supervision of a lawyer; and villages with neither paralegal nor legal education programs.

The study found that in Mozambique, in any village with a paralegal, almost every dispossessed woman asserted her land rights claim. However, if community leaders failed to resolve the case at the local level, paralegals operating on their own struggled to connect the women to higher level legal advice or assistance with drafting court claims. In contrast, women in villages where paralegals were connected to lawyers were more likely to go beyond the community level and bring their case to formal court, where decisions are more often in a woman's favor. The author concludes that while paralegals could lead women to challenge dispossession, the women tended to succeed only when those paralegals were connected with lawyers.

Several interventions combined legal empowerment approaches with the delivery of other basic services. These programs show how legal empowerment can be integrated into broader development efforts.

UNICEF combined birth registration with primary health and education services in Bangladesh, where only $9.8 \%$ of children under the age of 5 had their births registered as of $2006 .^{32}$ Birth registration is essential for accessing government services and, especially important for young girls, preventing child marriage through proof of age. In order to increase the birth registration rate, UNICEF trained health workers and teachers in the law and procedures governing registration. As a result, these professionals could register children who came in for immunizations or primary school enrollment-not only easing access to birth registration, but catching children whose families may not have sought out legal services at all. By 2009, due to the bundling of registration with other services and parallel capacity building of government, $53.6 \%$ of children under the age of 5 were registered, as measured by the UNICEF Multiple Indicator Cluster Survey (MICS).

In Kenya, several NGOs have integrated legal services into healthcare with support from the Open Society Institute Law and Health Initiative (LAHI). Integration can consist of placing a paralegal or other legal service provider in a health clinic and/or training healthcare providers to identify rights violations, give clients information on the law, and provide referrals for legal assistance and other services. Health providers could play a role similar to that of community-based paralegals, even as they carried out their healthcare duties.

The Harvard School of Public Health conducted a mixed methods evaluation that found trained health workers were able to assist their patients with legal documents and with accessing appropriate legal services. ${ }^{33}$ The evaluators concluded that health worker referrals improved client access to government authorities, additional health services, and assistance for dealing with other problems underlying poor health. For example, according to the evaluation findings, referrals to NGO-led alternative dispute resolution resulted in redress for rights violations and a sense of

\footnotetext{
32 UNICEF (2010).

${ }^{33}$ Harvard School of Public Health (2011).
} 
justice among participants. Clients served by health clinics with integrated legal services also showed an increase in practical knowledge on how to access other legal aid.

Our review yielded a significant amount of evidence-45 studies in all—on community-based paralegal strategies (we included 'citizen advice bureaus' in this category). ${ }^{34}$ This evidence suggests paralegals have significant potential as intermediaries who can help people bring good laws to life. Elsewhere we have suggested that community paralegals should be a core part of most legal systems, similar to the role that community health workers play in the delivery of healthcare. ${ }^{35}$ In comparison to the rich body of research on community health workers, ${ }^{36}$ however, the evidence on paralegals remains thin. As there are many paralegal efforts that have not yet been documented, ${ }^{37}$ future evaluative efforts might take advantage of existing programs to generate more knowledge on how paralegals work across diverse issues and contexts.

Ombudsman offices and human rights commissions were the two approaches for which we found the least evidence that met our definition of legal empowerment. We also found little relevant evidence on public interest litigation. All three of these approaches are often offered as a form of expert help, without an emphasis on the agency of their constituents. It would be useful to explore their potential to advance legal empowerment.

\section{Impacts}

One hundred ninety-one studies addressed impacts on 'citizens and consciousness'. of which all but eight identified at least one positive change. A smaller but still substantial number-111 studies-examined impacts on institutions. Of these, 89 claimed the legal empowerment intervention had a positive impact on institutional law/policy or practice.

Figure 4 illustrates the distribution of impacts within the broad category of 'citizens and consciousness'.

\subsection{Expanding Agency}

One hundred ten studies-68\% of all studies in the review-claimed legal empowerment interventions had a positive impact on agency. All but 18 of these interventions reported an increase in both willingness to act and actual action.

\footnotetext{
34 Admittedly, our organization Namati, which is focused on the community paralegal approach in particular, has had an outsize role in generating this evidence. Namati or its team members were involved in 10 out of the 45 total studies.

35 See, e.g., Maru (2006), pp. 428, 476.

36 See, e.g, Liu et al. 2011, p. 419; see also Singh and Sachs (2013).

37 For example, in July 2012, Namati, Global Rights, and the Open Society Justice Initiative hosted an African regional meeting attended by more than 50 paralegal organizations from twenty countries around the continent. In November 2012, a similar meeting was held in Indonesia, drawing together dozens of Southeast Asian paralegal groups.
} 


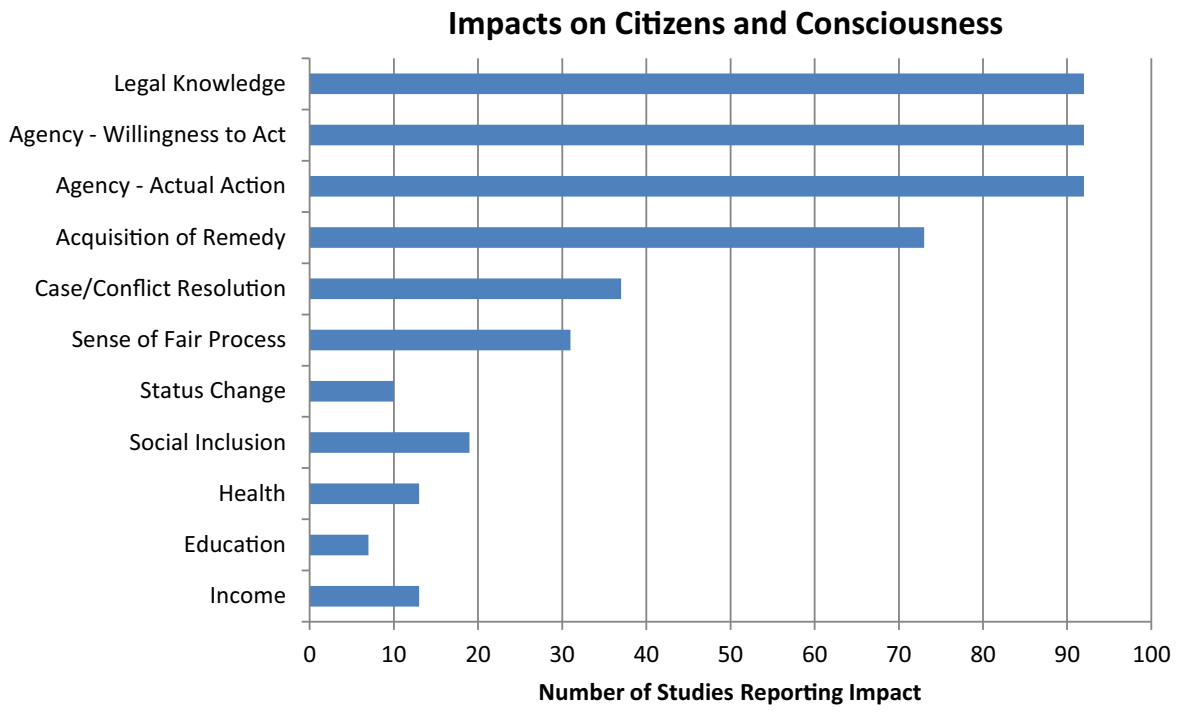

Fig. 4 Impacts on citizens and consciousness

Programs that included use of advocacy strategies were the most likely to influence participants' willingness to take action. Fifty-eight percent of advocacy interventions resulted in this type of increase in agency, as did $56 \%$ of community mobilization programs. Other strategies associated with positive impacts on willingness to act include legal literacy, strengthening of customary justice system, and community-based paralegal programs.

The two legal empowerment approaches that most frequently demonstrated an impact on actual actions taken by their constituents were 'citizen participation in governance' and 'citizen mobilization'. Both of these approaches tend to emphasize public, collective action. Other approaches commonly associated with increases in action include right to information, community monitoring, and legal literacy. In these situations, as with the following example from Nepal, the additional knowledge that participants gained from program activities or information requests may support the change in agency.

In Nepal, a USAID-supported program aimed at improving women's legal and economic empowerment contained three main activities: basic literacy training; legal literacy classes; and skills training such as weaving or poultry-raising. ${ }^{38}$ The three-month legal literacy classes taught women about basic rights and strategies for organizing into advocacy groups. The study of this program used two main indicators to measure impact. The first tracked the number of women who initiated joint action for social change. The second measured women's reports on influence in household decision making. The use of direct observations, focus groups, and key informant interviews generated data in both program and control sites in three different districts. The in-depth qualitative methods helped the research team

\footnotetext{
38 Malla Dhakal and Sheikh (1997).
} 
examine which of the three programmatic activities was most closely related to impact.

In the villages of intervention, women explained that prior to and at the early stages of the program, they did not understand the power of acting in a group. Later, as one participant explained, they learned that a 'group can do things individuals cannot'. Women formed associations to tackle issues from sanitation and health awareness to domestic violence and lack of female participation in community forest users' groups. The women credited the legal literacy classes in particular as providing the catalyst and courage for organizing social action. Overall, women who participated in the program initiated almost eight times more collective actions than women in control sites.

The intervention also influenced women's agency within the household. Several focus group participants reported that the legal literacy classes led them to challenge their husbands' unilateral spending decisions and to demand joint participation in financial matters. Women living in villages where all three program components were active participated $30 \%$ more in joint and individual decisions over use of income than women in the control sites.

\subsection{Legal Knowledge}

An increase in legal knowledge, like changes in both types of agency, was reported in 92 studies. Unsurprisingly, legal literacy was the approach that most frequently boosted legal knowledge. Seventy-five percent of programs with an explicit legal education component resulted in reported impacts on knowledge.

Legal aid programs and paralegal programs are both highly correlated with effects on legal knowledge. Legal knowledge was found to have increased in $69 \%$ of legal aid programs and $64 \%$ of community-based paralegal programs. This correlation suggests that legal aid providers are educating clients about laws and legal procedures in the course of resolving cases. Alternative dispute resolution, during which facilitators may draw on the law, led to changes in legal knowledge in $60 \%$ of studies.

Similarly, $53 \%$ of studies covering efforts to strengthen customary justice systems found positive effects on legal knowledge, likely because these programs tend to educate both the general public and traditional authorities on legal standards. In Bangladesh, Ain o Salish Kendra (ASK) trained local committees of women to monitor shalish, a traditional justice mechanism often led by elders in the community. ${ }^{39}$ This monitoring, along with legal education of the shalish panel members, reportedly led to the elimination of a particular marriage and divorce practice in the villages where ASK was active. The practice, which encouraged women who wanted to reconcile with an ex-husband to first marry another man, had resulted from misrepresentation of religious law.

Changes in legal knowledge may be a foundation for other impacts over time, including willingness to take action and pursuit of remedies or other entitlements. Researchers claimed the legal literacy program from Nepal, described above, not

39 Golub (2003b) p. 11. 
only increased women's knowledge of their rights, but also resulted in the participants planning social action campaigns and asserting themselves in household decision making. Yet in the study of a Tanzania and Mozambique-based paralegal program focused on women's land rights, also summarized above, the authors conclude increased legal knowledge alone was not sufficient to catalyze community action. Other aspects of the program, including paralegal support and even back-up support from a lawyer, were necessary for women to translate their legal knowledge into a successful fight for their land claim. More research into the contextual factors and program activities that allow impacts on legal knowledge to contribute to other types of change could underpin more effective program design and implementation. ${ }^{40}$

\subsection{Obtaining Remedies}

Apart from changes in agency and legal knowledge, the next most frequently cited positive impact on 'Citizens and Consciousness' was successful acquisition of a remedy, entitlement, or information. This type of impact was cited in 73 studies.

In Mexico, for example, Ciudadanos en Apoyo a los Derechos Humanos (CADHAC) supported prisoners with using the Law for Transparency and Access to Information. ${ }^{41}$ Under Mexican law, early release from prison is possible for good conduct. Yet most prisoners had no information on their behavior status, and a 2005 study found that the unit in charge of updating behavioral information did not often respond to requests to view personal files. CADHAC started assisting prisoners with using the Law for Transparency and Access to Information to gain access to prison files, including information on behavioral status and anticipated process for release. Although the Public Security Department initially denied these requests, a complaint filed by the prisoners with the Federal Institute for Access to Information (IFAI) resulted in the successful acquisition of the desired information. Armed with their new knowledge, the prisoners pushed forward early release procedures that had been stagnating for months or years. As of 2009, more than $40 \%$ of the requesters aided by CADHAC had achieved early release from prison in accordance with the law.

The institutions most often engaged in the successful pursuit of remedies or entitlements include ombudsman offices, formal courts, regulatory agencies, and service delivery agencies. In fact, all institutions except the military were engaged by legal empowerment efforts that led to acquisition of remedies. While the arbitration and adjudication roles of administrative agencies and the judicial branch may underpin this trend, more research would be useful to understand why relatively fewer impacts on remedies are reported in programs that interact with traditional authorities, including chiefs, elders, and customary courts.

\footnotetext{
${ }_{40}$ See, for example, African Development Bank and Asia Foundation, Legal Empowerment for Women and Disadvantaged Groups 47-48 (2009), available at https://asiafoundation.org/resources/pdfs/ LegalEmpowerment.pdf (describing relationship between legal awareness and active participation). See also Golub (2006), pp. 167, 176. See also Domingo and O’Neil (2014), pp. 46-48.

41 Guerrero Amparán (2009), pp. 257, 259.
} 


\subsection{Dispute Resolution}

Twenty percent of the studies in this review reported positive impacts on dispute resolution. The most common legal empowerment strategies employed in these interventions were mediation, legal literacy, and community-based paralegals.

An evaluation of the Carter Center's mobile paralegal program in Liberia used a baseline and follow-up survey structure with individual-level randomization to explore the effects of paralegal assistance with client cases. ${ }^{42}$ Following community education sessions, paralegals met with potential clients to verify the validity of the case. To avoid an ethical breach, paralegals handled any urgent cases immediately and excluded these from the study. Researchers then randomly assigned the remaining clients to either a treatment or control group. The treatment group received paralegal support from that point forward, while the control group was guaranteed access to the paralegal after three months. Clients in the control group were advised to take whatever actions necessary in the interim period to try to solve their case-both for ethical reasons and to ensure that the anticipation of paralegal support would not artificially lower non-treatment case outcomes. After three months, both groups answered questions about their experience in the intervening period.

The evaluation found that perceptions of fairness among paralegal clients increased by $34.8 \%$ and satisfaction with the resolution of their case increased $37 \%$, relative to the control group. Households with single mothers were $22.8 \%$ more likely to be receiving child support payments, compared to the control group. The data also displayed subsequent changes beyond case resolution itself, including increases in household and child food security that were measured through questions related to anxiety over food access, perceptions of sufficient quantity and quality of food, and other related factors.

Overall, the 37 programs that led to successful resolution of cases or disputes range across nearly all issue areas. The most common issue areas include family disputes, women's rights, intra-community disagreements, and natural resource rights. These interventions most often engaged traditional authorities, local-level courts, service delivery agencies, and local-level legislative representatives.

\subsection{Development Outcomes}

Proponents argue that legal empowerment equips people to overcome poverty. ${ }^{43}$ Conversely, increased spending on health and education, building of new infrastructure, and poverty reduction initiatives may fail to produce desired results without accountability, transparency, and public involvement. The existing evidence base suggests that legal empowerment strategies have been successful in improving health, strengthening educational learning, and increasing income.

\footnotetext{
42 Sandefur and Siddiqi (2013).

43 See, e.g., Banik 2009, p. 117; Golub and McQuay 2001; Sheldrick (2012). See also Pinzon Rondon (2015) (on the association of rule of law and health outcomes).
} 
Ten studies reported improvements in health indicators as a result of a legal empowerment intervention. The two most common approaches in these programs were community monitoring (in particular, community scorecards) and citizen participation in governance, followed by advocacy, legal literacy, and community mobilization interventions.

One well-known study on Uganda found that community monitoring led to dramatic improvements in both clinic utilization and health outcomes within a one year period. ${ }^{44} \mathrm{~A}$ randomized experiment on the effectiveness of community monitoring was conducted in 50 Ugandan communities -25 received the treatment and 25 served as controls-covering a total population of 55,000 households. In treatment communities, the program started with two meetings, one with health providers and one with the local population. At each meeting a community-based organization (CBO) presented a scorecard on the quality of healthcare at the local clinic compared to other nearby service providers and to government healthcare policy. The two groups then met together to develop an action plan, according to which the staff of the health clinic would improve the quality of services. Following the development of this plan, the communities decided how to organize ongoing monitoring of health service delivery, with support from the CBO in the form of follow-up meetings.

In just one year, utilization of health services increased by $15 \%$, vaccination rates improved, and waiting times at the clinics dropped in the intervention villages compared to the control group. Moreover, at the end of the program, the data showed under-five child mortality was $33 \%$ lower in treatment villages than in the control group, corresponding to 546 averted under-five deaths in the year following the program. The average weight of infants between 1 and 18 months of age also increased in the treatment villages during that year.

A main factor of success cited in the study was the provision of extensive information on clinic performance and government healthcare policy. Armed with this new knowledge, community members were better able to articulate their expectations and monitor health services, leading to increased effort from the health clinic staff and ultimately positive impacts on health.

While the Bjorkman and Svensson piece is one of the most striking examples of improvement in health indicators, especially in such a short period of intervention, this study is not the only evidence on how legal empowerment can improve health. In Maharashtra, India, a program using community scorecards, health outreach, and a policy awareness campaign also led to health outcomes. To better incorporate consultations on clinic quality with end-users of health services, an intervention led by the Tata Institute of Social Sciences (TISS) and the World Bank-sponsored Jalswarajya Project conducted a health policy awareness campaign and trained community facilitators. ${ }^{45}$ The facilitators built on the new policy knowledge in their areas by leading groups of villagers and service providers through separate assessment processes to generate scorecards on clinic performance. An interface

\footnotetext{
44 Bjorkman and Svensson (2009), pp. 735, 736.

45 Murty et al. (2007).
} 
meeting then provided a forum to discuss concerns with the health clinic and to create a plan to improve services at the clinic.

An evaluation of the program found an increase in clinic utilization rates, measured by the regularity of check-ups for children from birth to age six, as well as actual health outcomes. In a period of just six months, malnutrition in several villages also dropped. For example, the percentage of normal weight children rose from 56 to $69 \%$ in the area served by Thosegar Primary Health Center and from 67 to $73 \%$ in the area served by the Limb Primary Health Center. Not only did client satisfaction go up, but several villages demanded the scorecard process be repeated after three or six months, showing the value the local communities saw in the intervention. The success of the pilot project led to an expansion in 41 villages, with plans to eventually cover the whole district.

In addition to community monitoring initiatives, assessments of paralegal-type interventions have also found changes in health outcomes. Jay Wiggan and Colin Talbot conducted a literature review on the impact of welfare rights advice services, which play a role similar to that of community-based paralegals. ${ }^{46}$ These offices work with hard-to-reach populations to encourage awareness and take-up of available tax credits, health benefits, and other services, and to assist people with navigating the entitlement system. As a result of using the advice service, some clients reported less anxiety over finances as well as a better ability to communicate with their general physician, leading to more effective health treatments. Wiggan and Talbot find that clients of the welfare rights advice services not only receive additional financial resources through pursuing welfare entitlements, but also experience significant improvements in mental health and some gains in physical health.

In other studies, improved functioning of health clinics was measured during or after legal empowerment interventions. More research could be conducted in these places to examine if improved effort and increased availability of clinic staff-a change in institutional practice-actually led to gains in health outcomes of the community, as occurred in the examples from Uganda and India above.

Seven studies make connections between legal empowerment and positive effects on education outcomes, often measured by improved test scores or a decreased percentage of students failing annual exams. Similar to health-related initiatives, these programs tend to use legal literacy, community mobilization, and community monitoring strategies.

Several studies covered interventions that enhanced the capacity of parents to take part in the governance of education services. In Kenya, concerns arose about the quality of teaching, as governments hired low-paid contract teachers to deal with increases in enrollment after the introduction of free primary school education. In cooperation with International Child Support (ICS), an experiment examined the effects of empowering parents through 'School Based Management' (SBM). ${ }^{47}$ As part of a committee, parents had the power to provide input in the hiring process,

\footnotetext{
46 Wiggan and Talbot (2006).

47 Esther Duflo et al. (2007).
} 
monitor compliance with national education policy, and carry out regular teacher attendance checks.

The School Based Management scheme led to much greater increases in student test scores, compared to hiring more contract teachers alone, according to a standardized math and literacy test administered before and directly after the intervention. The contract teachers at institutions with SBM were also 50\% less likely to be a relative of an existing salaried teacher than at other schools covered by the evaluation, suggesting a reduction in nepotism where parents have substantial involvement in school governance. One year after the intervention, the average gains in student learning did start to fade, though at a slower rate in schools where parents had been involved in management.

As this example illustrates, while legal empowerment may contribute to development outcomes, more research is needed on medium term impact, especially the factors that allow for positive health and education outcomes to be sustained over time and at scale.

The evidence on certain legal empowerment approaches shows relatively more contribution to development outcomes-community monitoring, paralegals or citizen advice bureaus, advocacy, and legal literacy.

While several studies claim positive impacts on access to healthcare or health outcomes among clients of citizen advice bureaus in Western Europe, little evidence exists on what community-based paralegals in the developing world have contributed in this realm. The example from Liberia described above is an exception. There are a number of paralegal programs dedicated to helping people exercise basic rights to healthcare. ${ }^{48}$ More research could be conducted on those programs - to ascertain not only the remedies to specific grievances, but also longerterm changes in the lives of clients, such as improved physical well-being and wealth. Where paralegals rarely deal with health-related cases, organizations might consider adding specific training modules so that paralegals are able to address accountability in health services.

\subsection{Impacting Institutions}

The five approaches most likely to contribute to institutional impact were ombudsman offices, human rights commissions, public interest litigation, advocacy, and community monitoring. (See Fig. 5) Of these five, the first three appear in a small proportion of studies in the review-16 studies total. Advocacy and community monitoring appear in 120 studies total; they were the most common strategies by which legal empowerment interventions influenced institutions.

We coded whether the institutional change was in law or in practice, and the level of government at which it took place (local, provincial/state, or national). Table 3 shows the distribution of positive impacts across both dimensions.

Of all effects on institutions, the impacts of the legal empowerment interventions studied tended to be concentrated in local level changes in practice, which was

48 See, for example, Feinglass et al. (2016). 


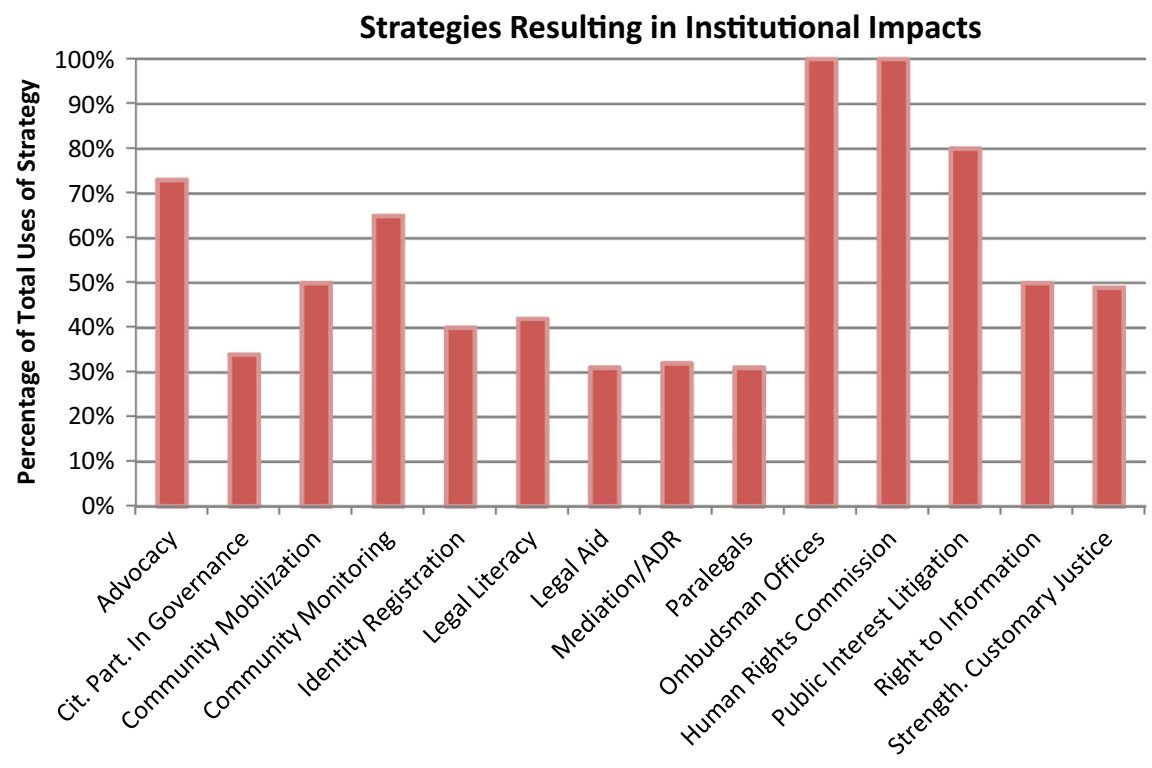

Fig. 5 Strategies resulting in institutional impacts

Table 3 Distributions in institutional change (number of studies)

\begin{tabular}{llcc}
\hline & National & Provincial or state & Local \\
\hline Law/policy & 20 & 6 & 13 \\
Implementation/practice & 15 & 17 & 59 \\
\hline
\end{tabular}

reported in 59 studies. This is logical, given that much of legal empowerment work is local in nature.

Overall, there is much more evidence of impacts on the implementation of law than on the law itself. A case study about an intervention on primary education in Malawi is an example. ${ }^{49}$ In the mid-to-late 1990s, the quality of education in Malawi remained stagnant despite the introduction of free primary education and increased government investment. The Civil Society Coalition for Quality Basic Education (CSCQBE), a group of 67 civil society organizations, started an initiative to promote accountability in Malawi's education sector. CSCQBE suspected corruption and mismanagement at the district level, where spending of education funds takes place. The coalition set out to use a combination of the Public Expenditure Tracking System (PETS) and 13 district networks that support community-based groups in monitoring education budgets. Through technical assistance, these networks aimed to increase the capacity of parent-teacher

\footnotetext{
49 Vivek Ramkumar, 'Our Money, Our Responsibility: A Citizen's Guide to Monitoring Government Expenditures' (Int'l Budget Project, 2008), available at http://internationalbudget.org/wp-content/ uploads/Our-Money-Our-Responsibility-A-Citizens-Guide-to-Monitoring-Government-ExpendituresEnglish.pdf, pp. 31-32.
} 
associations and other community members to ensure accountability in spending at the school level. PETS and other monitoring provided a wealth of information on government spending, budgets versus actual expenditures, and procurement and delivery processes. CSCQBE organizations and their constituents analyzed the information and undertook large-scale advocacy and media campaigns to pressure districts into investing properly in education.

The case study claimed several changes in institutional practice came about due to this advocacy. The positive changes included a shift in the way the local government supports students. More funds were provided to students with special needs through allocations for targeted materials in their classes. The advocacy also helped teacher salaries get paid on time and for schools to stay open despite funding challenges.

More than half of institutional change in the evidence we reviewed relates to the issue of accountability for basic services. Most of these changes involved implementation of existing policies-with 32 interventions affecting local practice and 13 interventions influencing provincial level practice. Community monitoring is the most common approach in these programs. There is also a trend in the institutions engaged in these programs - the majority interacted directly with service delivery agencies. The changes in local practice are mostly improvements in the operations of schools, health clinics, and other public entities through better attendance, effort, and accountability of individual service providers. Eleven interventions relating to the issue of essential services achieved positive changes in national policy.

Other issue areas for which evidence shows some institutional change are corruption (36 interventions), women's rights (29 interventions), abuse of formal authorities (24 interventions), and land and natural resource rights (20 interventions).

The evidence reports more changes in law or policy at the national level than at provincial or local levels, regardless of issue area. When policy changed as a result of an intervention, the programs tended to use legal empowerment approaches such as public interest litigation, advocacy, ombudsman offices, and-like the following intervention in Delhi-right to information laws.

Parivartan, a civil society group focused on corruption and other issues of justice, started an intervention that combined community monitoring, advocacy, and the Delhi Right to Information Act to push for better delivery of subsidized grain through the Public Distribution System (PDS). ${ }^{50}$ Parivartan mobilized over 300 people to access their PDS food grain records through the RTI law and analyze the information against the amount of subsidized grain they had actually received. The people then attended public hearings with government officials to expose the inconsistencies. The effort uncovered that $87 \%$ of grain and $94 \%$ of rice had been sold on the open market rather than made available to families living below the poverty line. This use of the law and public pressure not only led to some improvements in distribution the next year, but based on this grassroots success, Parivartan and its constituents successfully pushed for the institutionalization of scrutiny through public hearings within Delhi's PDS mechanism.

50 Pande (2008), p. 52. 
An important frontier for the legal empowerment movement going forward is translating the lessons of grassroots efforts into large-scale policy change. The existing studies suggest that such change is possible, but there is a great deal more to learn about the programmatic and contextual factors that determine whether a particular attempt succeeds.

The uneven distribution of evidence between 'citizens and consciousness' on the one hand and 'institutions' on the other may be due to the ease with which each type of change can be measured. Improvements in legal knowledge are captured by pre and post-tests, increased willingness to take action by qualitative interviews, and enhanced education or health outcomes by development indicators, student test scores, and clinic statistics.

Proving the definitive contribution made by legal empowerment on government is much more difficult, especially when the desire is to link a single intervention to large-scale processes of change. Legal empowerment organizations have less control over parliamentary decision making than they do over the amount of learning at, say, a community-level training. ${ }^{51}$

Half of the evidence examining institutional impact is in the form of a case study. Many of these studies link a legal empowerment intervention to changes in institutional policy or practice through a narrative based on anecdotal evidence. Other pieces of evidence, including some case studies, use a variety of qualitative and quantitative methods to explore impacts on institutions.

As noted above, accountability of basic services is a relevant issue in more than half of the evidence linking legal empowerment to institutional impact. Observations of local service providers, such as teachers or nurses, or even institutional records such as food distribution charts can illustrate changes in the frequency and quality of service delivery. The views of the local community can also contribute to understanding institutional impact. In Uttar Pradesh, India, a randomized control trial assessed changes in local delivery of social services following a legal literacy campaign about entitlements. ${ }^{52}$ The researchers used surveys and focus groups to collect villager reports on visits by nurse midwives, delivery of prenatal supplements, requests for excess school fees, and other outcome measures before and after the intervention in both treatment and control sites.

Where studies aim to understand how legal empowerment interventions influence closed-door policy decisions or opaque national-level reform, researchers often seek to directly interview relevant authorities. Officials involved in policy making or enforcement can provide detailed information on the factors most influential in producing specific institutional decisions. HakiElimu's education-related legal literacy and advocacy effort in Tanzania was connected to institutional impact by insight gathered through interviews of authorities. ${ }^{53}$ The authors conclude that

\footnotetext{
51 See Golub (2003b), p. 175.

52 Pandey et al. (2007), p. 1867.

53 'Quality of Education Reforms: The Case of HakiElimu's Campaign of 2005-2007', Int'l Budget Partnership (2007), available at http://internationalbudget.org/wp-content/uploads/LP-case-studyHakiElimu-summary.pdf.
} 
HakiElimu's campaign was a major catalyst for change, though other factors also helped push the government to reform.

To assess how the Public Affairs Centre's citizen report cards (CRCs) intervention affected public service delivery in Bangalore, India, researchers also conducted interviews with state agency officials. ${ }^{54}$ The researchers chose 19 individuals expected to be familiar with both the CRC findings as well as any government utilization of the data.

These interviews illuminated the reactions of officials to the CRC process as well as the ways in which the intervention influenced reform decisions. For example, some officials reported that, as a result of the CRC findings and advocacy pressure from the public, their agency initiated new staff training programs. The training was intended to improve responsiveness to citizens, one of the factors covered in the report cards. Other officials established mobile counters to ease bill payment for public services after seeing the report card data. By using interviews to gather data from government staff directly, the researchers could elicit exactly how the CRC intervention combined with other factors to produce reform-at least partially linking those institutional changes to the legal empowerment intervention itself.

Historical inquiry is not well represented in the collection of existing legal empowerment evidence. However, looking to history is necessary to understand what causes governments and other institutions to change over the long term. ${ }^{55}$ Other longitudinal studies that examine medium to long-term impact may also help build the evidence base on institutional change.

\subsection{Negative and Null Impacts}

As explained above, nearly all pieces of evidence collected in this review claim at least one positive impact. Only nine studies are explicit about negative changes that occurred during program implementation. A larger number-49 studies, $25 \%$ of the total evidencesought to measure a certain type of change, but in the end reported that no impacts of that type were detected. The finding of no change does not necessarily mean the program failed in obtaining its goals - the study may have been too early to capture all effects or the evaluation methodology itself may have had some flaws. The researchers of a study may have attempted to measure a type of impact that program designers did not actually intend to create. The null impacts are distributed fairly evenly across all legal empowerment strategies, so no clear trends emerge. More research on null and negative impacts will help to determine the factors that may facilitate or obstruct change.

\section{Issues}

Legal empowerment efforts tend to focus on certain issue areas. Figure 6 illustrates the most common issue addressed in this collection of evidence was accountability for basic service delivery.

\footnotetext{
54 Ravindra (2004).

55 See Woolcock et al. (2011), p. 70 for a useful discussion of how work by historians can and should inform development policy.
} 


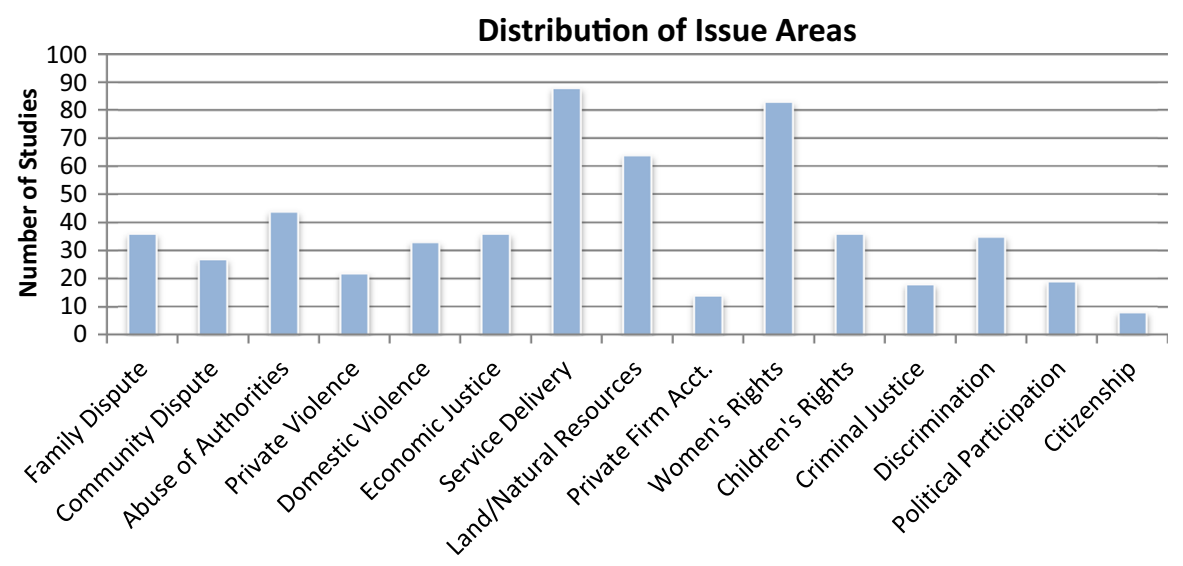

Fig. 6 Distribution of issue areas

The second most common issue area was women's rights, which itself cuts across many other issues. In the following example from Honduras, a grassroots organization used legal literacy and advocacy strategies to build support around several interlinked issues-women's rights, labor rights, and accountability of private firms.

Colectiva de Mujeres Hondureñas (CODEMUH), a grassroots women's collective in Honduras, launched a movement to protect the rights of women working in maquilas (textile factories) across the country. ${ }^{56}$ Women were underpaid for the long hours they worked, faced poor conditions, and experienced frequent rights violations at the hands of their employers, including instances of women being fired for becoming pregnant.

With support from Oxfam and the Institute for Social Research and Advocacy, CODEMUH began a campaign on occupational health and labor rights by building evidence on the risks and violations women faced at work. The organization used the information to advocate with the private factories, put pressure on the government, and spread awareness through the media. CODEMUH conducted legal education and organizing events with women who worked in maquilas, so that these women had the knowledge, skills, and confidence to see themselves as agents of change and contribute to the advocacy. CODEMUH built an alliance with national and regional labor rights efforts in order to sustain pressure at multiple levels. In 2006, CODEMUH became the first women's organization to march alongside traditionally male-dominated unions on Labor Day.

The multi-faceted campaign increased the public interest in labor rights in the maquilas, measured through monitoring participation in related radio and television shows. According to the case study, the intervention also increased maquila workers' awareness of their own rights and of the responsibilities of factory owners.

56 Arita (2008). 
The pressure exerted on the government by the civil society alliance led to a review of the Honduran Labor Code. The government showed their renewed attention to working conditions in the maquilas through additional monitoring visits, even if the oversight remained unsystematic. The researchers concluded that attention from multiple stakeholders led to improved conditions in some factories, but improvements in law enforcement and ongoing public pressure is needed for sustainable change.

In some issue areas, legal empowerment evidence is relatively thin. Citizenshiprelated interventions are less common or less studied than other issues. Just eight studies focused on citizenship rights programs. Business rights, counted as part of economic justice, only appeared in four studies. More research is needed on these issue areas, as well as private firm accountability and criminal justice.

\section{Engaging Institutions}

Even interventions whose demonstrated impacts are largely at the level of citizens and consciousness often engage some form of institution. A paralegal program might successfully help clients make use of a police disciplinary board, for example, without creating demonstrable changes to either the policy or the practice of the police.

Of all the interventions in this review, the type of institution most often engaged was administrative agencies, which includes service delivery entities, regulatory agencies, and public-private enterprises. ${ }^{57}$ In total, 90 interventions engaged with at least one administrative body. Of these, 80 interventions interacted with service providers and 34 interventions interacted with regulatory agencies-some programs engaged both types of institutions.

The most common strategies used when engaging with service delivery agencies were right to information laws, advocacy, participation in governance, and legal literacy. Almost all studies on paralegal or citizen advice bureau efforts explicitly mentioned navigating administrative processes.

Legal empowerment programs often engage traditional authorities in the process of navigating between formal and customary legal systems. The NGO Paralegal Advisory Services Institute (PASI), for example, trained a network of village mediators to resolve justice issues in their communities in a culturally-appropriate manner while considering the human rights elements - such as gender equality-in every case. ${ }^{58}$ The mediation service provided an alternative to traditional dispute resolution, but PASI still engaged Chiefs by including them in the village mediators' training. Clients also retained the option to hold an open forum with the Chief if mediation failed. The village mediators resolved hundreds of disputes through alternative dispute resolution. Yet a case study on the impact of the program

\footnotetext{
57 See Maru and Moy (2013), pp. 59, 63-65, for a discussion of these three categories.

58 Meneses (2011).
} 
cited the engagement with traditional authorities as a key factor that provided clients with several options for case resolution, increased the community-level support for the program, and led to more confidence in the justice system overall.

Unlike engagement with traditional authorities, there is little evidence on programs that interacted with the military, national level courts, or hybrid publicprivate enterprise. Only 16 interventions engaged directly with private firms. ${ }^{59}$ More research is needed on what legal empowerment strategies can achieve through interacting with these institutions.

In addition, just $26 \%$ of the studies reviewed used the media to further program goals. Those studies involved several legal empowerment approaches, including advocacy, community mobilization, community scorecards, and right to information. However, considering that naming and shaming through media pressure is often used in the larger human rights field, more inquiry into the use of media in legal empowerment interventions would be useful.

\section{Regime Type}

Most existing research on the impact of legal empowerment covers countries that are 'free' or 'partly free' ${ }^{60}$ Of the 193 studies coded for political regime (not including studies covering five or more national contexts), only 10 studies focused on a 'not free' country.

There seems to be little difference between the prevalence of positive impacts of legal empowerment programs implemented under 'free' and 'partly free' regimes. Of the 77 studies focused on 'free' regimes, 99\% had at least one positive outcome, compared to $98 \%$ among the 106 studies conducted in 'partly free' countries. The prevalence of null impacts in interventions in both 'free' and 'partly free' countries was close to $25 \%$, the overall average in the evidence. Of the six studies that showed no positive outcomes, three covered interventions in free countries, two in partly free countries, and one in a not free country. The inability to differentiate positive and negative outcomes based on regime type likely relates to the overall positive publication bias.

We have little understanding about what is possible for legal empowerment to achieve in repressive regimes. Of the ten interventions falling under countries that are 'not free,' two took place in the Democratic Republic of the Congo (DRC), plus one each in Angola, Rwanda, Somalia, South Sudan, Zimbabwe, Afghanistan,

\footnotetext{
59 These interventions are concentrated in a few issue areas. Seven of these programs fell within the land and natural resource rights issue area. Eight of the studies involving interactions with private firms related to delivery of basic services, four related to corruption, and five touched on economic injustice, such as business rights, labor, or housing.

60 Freedom House's Freedom in the World Survey 2012, supra n. 18, provided a proxy for coding the political regimes relevant to each piece of evidence.
} 
Yemen, and Burma. These efforts used strategies such as strengthening customary justice systems, legal literacy, and participation in governance. ${ }^{61}$

The gap in knowledge related to 'not free' countries may be driven more by research priorities than a dearth of legal empowerment initiatives in situations of repression. In Cambodia, for example, which Freedom House rates as 'not free,' there is an active civil society that makes use of legal empowerment strategies. In 2010 and 2011, the International Land Coalition supported projects that used legal literacy and paralegal services to advance women's land rights. ${ }^{62}$ Also in Cambodia, the Community Legal Education Center implements legal literacy, legal aid, and litigation programs to improve access to justice, land rights, and labor rights. ${ }^{63}$ Similarly, while Somalia and South Sudan both received 'not free' ratings by Freedom House and are represented once each in this review, we found no evaluations of the ongoing community-based paralegal programs from these nations. ${ }^{64}$

It would be useful to have a greater understanding of how these efforts work, and what legal empowerment strategies can achieve in adverse political circumstances.

\section{Scale}

Ninety-one studies in this review explicitly identified the scale of intervention, or the number of people included in a program. (See Fig. 7)

Of the studies that specified scale, the most common program size was between 1000 and 10,000 people. The second most common scale of intervention was the smallest range-under 1000 people. Interventions affecting more than a million people were the least represented in this body of evidence.

Ultimately, the legal empowerment field will need to prove its ability to have impact at a large scale. More evidence on large-scale programs is crucial. It is not necessary that the evaluations of such programs be large-scale themselves, however. With sound sampling strategy, an evaluation of a smaller number of field sites can make claims about the impact of the intervention as a whole.

\footnotetext{
61 Waldorf points out, in a similar vein, a lack of evidence on the role of legal empowerment in transitions away from authoritarianism and conflict. See Waldorg (2015), p. 229.

62 International Land Coalition, 'Women's Legal Empowerment: Lessons Learned from CommunityBased Activities', ILC Briefing Note (2012), available at http://www.landcoalition.org/sites/default/files/ publication/1267/WLEP\%20EN\%20final\%20WEB.pdf.

63 For more information, see Community Legal Education Center, http://www.clec.org.kh. Last accessed 13 February 2015.

64 Paralegal organizations from each nation attended a regional meeting on paralegals co-hosted by Namati, Global Rights, and the Open Society Justice Initiative in Uganda in July 2012.
} 


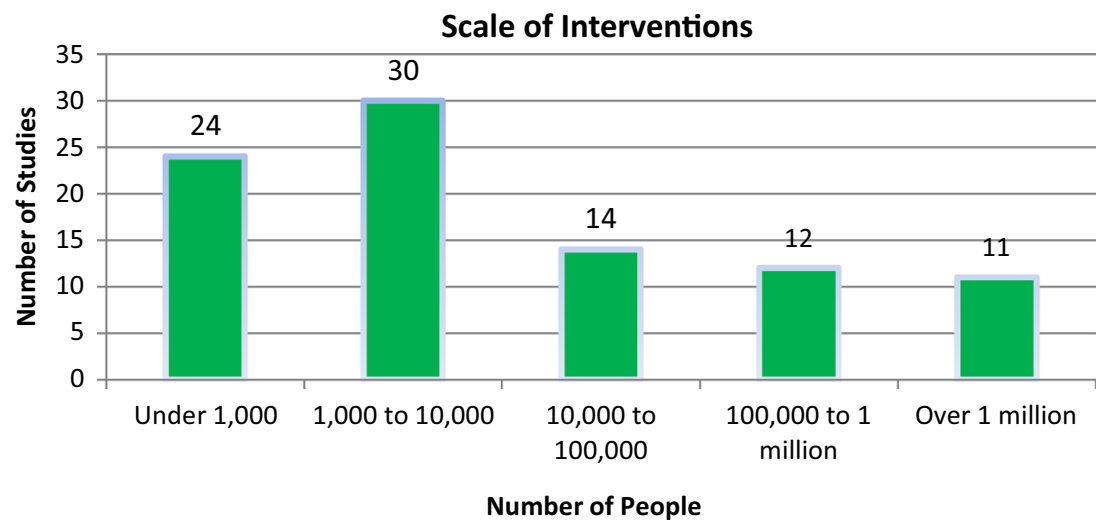

Fig. 7 Scale of interventions

\section{Conclusions and Recommendations for Further Research}

Substantial evidence exists on the impact of legal empowerment efforts around the globe. The evidence suggests legal empowerment has led to a range of changes: increases in legal knowledge and community participation, the resolution of disputes, improvements in health outcomes, and changes in institutional policy and practice.

Yet despite this wealth of information, there are still gaps in our understanding of legal empowerment. New research would be useful to fill these gaps. Unlike some scientific research, we do not imagine that we will ever arrive at a definitive answer to a question like 'which legal empowerment strategy is most effective in repressive regimes.' We recognize that all legal empowerment interventions are sui generis to some extent-interacting with the particularities of any given context. But we are convinced that more information about experiences across borders and approaches will benefit practitioners grappling with their own unique challenges. We are not aiming for recipes, but rather for the wisdom with which to make informed judgments about legal empowerment practice.

\subsection{Gaps in the Existing Evidence}

- Most evidence about institutional change is concentrated on improvements in the practice of local governments. Further research should examine how legal empowerment approaches can affect policy at the national level. Longitudinal research and historical inquiry may be appropriate to advance our understanding of complex processes of institutional change.

- Longitudinal studies can also examine long term impacts on citizens. Following up with clients several months or years later can produce insight into how the experience changed aspects of attitudes, behavior, and agency not seen in the short-term. 
- Community monitoring and citizen advice bureaus are the strategies most often associated with gains in education, health, and income. Paralegals also work in this realm, through helping clients hold service providers accountable, navigate administrative processes to obtain public benefits, and access referrals. Further study could explore the impact of paralegals on development outcomes.

- In general, while this review includes 45 studies on community-based paralegals or citizen advice bureaus, paralegal efforts would benefit from greater study, and we know that there are many programs that have not yet been examined.

- The evidence claims a range of impacts produced through legal literacy campaigns, but little is known about the precise mechanisms through which legal knowledge can lead to further changes, such as increased agency. Investigations into when and how increased knowledge underpins other changes will strengthen the design of legal empowerment programs.

- More research would be useful on the role of human rights commissions, ombudsman offices, public interest litigation, and identity document registration in advancing legal empowerment. Where these strategies are not part of legal empowerment efforts, implementing organizations might experiment by adding strategic use of public advocacy institutions or PIL to their current work.

- Existing evidence does not fully address how legal empowerment initiatives can achieve success when engaging with certain institutions, especially those other than administrative agencies. More research is needed on programs that engage with private firms and the military.

- Most existing evidence examines interventions at a small scale. For the field to mature, it will be essential to generate more evidence on the impact of legal empowerment at a large scale.

- We have little understanding about what is possible for legal empowerment to achieve in repressive regimes. Future research should study how legal empowerment interventions work in 'not free' contexts. Legal empowerment organizations might also consider increasing their engagement in such countries.

\subsection{Questions for Further Inquiry}

Several additional questions could be explored by further research efforts on legal empowerment. We were unable to address these questions in this review, because of time constraints and the fact that many studies did not explicitly address these concerns. We encourage authors of future legal empowerment evaluations to include these questions in order to advance understanding of the dynamics underpinning program success.

- Actors-Who designed and implemented the program? Is there a partnership between multiple actors, such as an international NGO and local communitybased organization, and if so, how does the relationship function? Are certain actors or combinations of actors more successful than others? 
- Funding-Is the intervention funded by international donors, national agencies, individual donations, or community contributions? Does the funding source affect the success of the program or the community's sense of ownership?

- Collaborative versus adversarial orientation-Does the intervention work in collaboration with government or private firms, or in direct opposition? Public interest litigation is clearly on one side of the spectrum while other strategies, such as the work of community-based paralegals, could take either approach. How do programs balance between the two? In what circumstances is each orientation most effective?

- Adapting to context-One of the great lessons from the history of rule of law initiatives is that a one-size-fits-all approach is not effective-programs must adapt to local context. ${ }^{65}$ We observe a great amount of variation among legal empowerment efforts, even among programs with a common approach. Some of this variation is likely context adaptation. More inquiry would be useful to understand how these adaptation decisions are made and the effect these choices have on results.

- Opportunity costs-How much impact does each intervention produce per dollar spent? How does that result compare with alternative uses of the money? Few studies explicitly address program costs, or break the total down into per unit costs. Understanding the cost-effectiveness of legal empowerment approaches may help implementers make strategic choices under resource constraints.

- Other contextual factors-This review took into account whether or not political context influences program outcomes. There are many other potential determinants of program success, including demographic distributions, social norms, levels of tolerance, power differentials, and so on. Coding for and analyzing these factors may uncover additional trends related to the effectiveness of legal empowerment.

'Access to justice for all' is now part of the Sustainable Development Goals, the global development framework that succeeds the Millennium Development Goals. The evidence in this review suggests that the legal empowerment movement has concrete means by which to contribute towards the achievement of that goal. The existing evidence provides a rich portrait of the strategies that legal empowerment organizations deploy, and the impact they create. Governments and civil society groups should draw on this evidence as they seek to scale up their efforts. Equally, they should invest in new research, so that the evidence base will expand alongside the practice. A living, growing body of knowledge will allow for smarter, more informed decisions in the pursuit of justice.

\footnotetext{
65 See, e.g., Trubek and Galanter (1974), pp. 1062, 1070-1072. Trubek and Galanter's famous article is said to have marked the death of the law and development movement of the late 1960s and early 1970s. Trubek and Galanter argued that U.S.-sponsored efforts to support, among other things, legal education and legal aid in the third world were misguided and likely to fail because of their reliance on an idealized, American-centered, 'liberal legalism' model of law and society.
} 
Open Access This article is distributed under the terms of the Creative Commons Attribution 4.0 International License (http://creativecommons.org/licenses/by/4.0/), which permits unrestricted use, distribution, and reproduction in any medium, provided you give appropriate credit to the original author(s) and the source, provide a link to the Creative Commons license, and indicate if changes were made.

\section{References}

Arita J-C (2008) A life with dignity: Honduran women raising voices to improve labor standards, speaking out: programme insights. Oxfam

Banik D (2009) Legal empowerment as a conceptual and operational tool in poverty eradication. Hague J Rule Law 1:117

Bjorkman M, Svensson J (2009) Power to the people: evidence from a randomized experiment on community-based monitoring in Uganda. Q J Econ 124(735):736

Brundage J (2008) The Medieval origins of the legal profession: canonists, civilians and courts

Commission on Legal Empowerment of the Poor, Making the law work for everyone 1, p. 3. http://www. undp.org/content/dam/aplaws/publication/en/publications/democratic-governance/legal-empowerment/ reports-of-the-commission-on-legal-empowerment-of-the-poor/making-the-law-work-for-everyonevol-ii_-english-only/making_the_law_work_II.pdf. Accessed 8 December 2017

De Renzio P, Azeem V, Ramkumar V (2006) Budget monitoring as an advocacy tool: Uganda Debt Network 4'. Available at http://internationalbudget.org/wp-content/uploads/Budget-Monitoring-asan-Advocacy-Tool-Uganda-Debt-Network-Full-Paper-English.pdf

Deininger K, Feder G (2009) Land registration, governance, and development: evidence and implications for policy. World Bank Res Obs 24:233

Domingo P, O’Neil T (2014) Overseas Development Institute. The politics of legal empowerment: legal mobilization strategies and implications for development, pp 13-17

Duflo E, Hanna R, Ryan SP (2010) Incentives work: getting teachers to come to school. Am Econ Rev 102:1241-1243

Duflo E, Dupas P, Kremer M (2007) Peer effects, pupil-teacher ratios, and teacher incentives: evidence from a randomized evaluation in Kenya. Available at http://citeseerx.ist.psu.edu/viewdoc/ download?doi=10.1.1.376.5394\&rep=rep1\&type=pdf

Feinglass E, Gomes N, Maru V (2016) Transforming policy into justice: the role of health advocates in Mozambique. Health Hum Rights. 22 September 2016. Available at https://www.hhrjournal.org/ 2016/09/transforming-policy-into-justice-the-role-of-health-advocates-in-mozambique/

Franco A, Malhotra N, Simonovits G (2014) Publication bias in the social sciences: unlocking the file drawer. Science 345:1502-1504

Freedom House (2015) Methodology: freedom in the World 2012. https://freedomhouse.org/report/ freedom-world-2012/methodology\#.VN6O17-SHFI. Accessed 13 Feb 2015

Gaventa J, Barrett G (2012) Mapping the outcomes of citizen engagement. World Dev 40:2399

Gerrero Amparán JP (2009) The right to know in Mexico: the challenge of dissemination, in focus on citizens: public engagement for better policy and services. OECD, pp 257, 259

Glick D, McCorkle C, Patterson A, Victurine R, Dickinson J (1994) Tropical research and development, 'sustainable uses for biological resources (SUBIR) Project: Phase 1 Evaluation'. Available at http:// pdf.usaid.gov/pdf_docs/PDABP379.pdf

Golub S (2003a) Beyond rule of law orthodoxy: the legal empowerment alternative. Carnegie Endowment for Int'l Peace Paper no 41

Golub S (2003b) Non-State Justice Systems in Bangladesh and the Philippines. http://siteresources. worldbank.org/INTJUSFORPOOR/Resources/GolubNonStateJusticeSystems.pdf, p. 11

Golub S (2006) Legal empowerment: impact and implications for the development community and the World Bank. World Bank Legal Rev 2(167):176

Golub S (2010) What is legal empowerment? An introduction. In Golub S (ed) Legal empowerment: practitioners' perspectives, pp 9, 17

Golub S, McQuay K (2001) Legal empowerment: advancing good governance and poverty reduction, in law and policy reform at the Asian Development Bank

Harris L (2004) In the shadow of slavery. University of Chicago Press, New York, pp 380 
Harvard School of Public Health (2011) Evaluating the integration of legal support and health care in Kenya: findings from the second phase of the evaluation

Johnstone N (2011) Bush justice in Bougainville: mediating change by challenging the custodianship of custom. In: Harper E (ed) Working with customary justice systems: post-conflict and fragile states. International Development Law Organization, pp 15, 22-24

Kapur A (2011) Two faces of change: the need for a bi-directional approach to improve women's land rights in plural legal systems. In Erica Harper (ed) Working with customary justice systems: postconflict and fragile states. International Development Law Organization, pp 73, 82-87

Knight R, Adoko J, Auma T et al (2012) Protecting community lands and resources: evidence from Liberia, Mozambique, and Uganda

Kremer M (2003) Randomized evaluations of educational programs in developing countries: some lessons. Am Econ Rev 93(102):104-105

Kurze A, Lamont C, Robins S (2015) Contested spaces of transitional justice: legal empowerment in global post conflict contexts revisited. Int J Hum Rights 19:260

Liu A, Sullivan S, Khan M et al (2011) Community health workers in global health: scale and scalability. Mt Sinai J Med 78:419

Mahoney J (1998) Green forms and legal aid offices: a history of publicly funded legal services in Britain and the United States. Saint Louis University Public Law Rev 17(266):223-240

Malla Dhakal R, Sheikh MM (1997) Breaking barriers, building bridges: a case study of USAID/Nepal's SO3 Women's Empowerment Program. Asia Foundation

Maru V (2006) Between law and society: paralegals and the provision of justice services in Sierra Leone and worldwide. Yale J Int L 31(428):476

Maru V (2010a) Access to justice and legal empowerment: a review of World Bank Practice. Hague J Rule Law 2:259

Maru V (2010b) Allies unknown: social accountability and legal empowerment. Harv J Health Hum Rights 12:83

Maru V, Moy A (2013) Legal empowerment and public administration: a map of the landscape and three emerging insights. In: Golub S, Berry D, Epstein K, Golub S (eds) Justice initiatives: legal empowerment, pp 59, 63-65

Meneses MP (2011) Malawi: the Malawi village mediation program: promoting social cohesion and protecting rights. United Cities and Local Governments Briefing Paper. Available at http://www. uclg-cisdp.org/sites/default/files/Malawi_2010_en_FINAL.pdf

Muchabaiwa LB (2010) Gender-sensitive and child-friendly budgeting in Zimbabwe. In: McNeil M, Malena C (eds) Demanding good governance: lessons from social accountability initiatives in Africa. World Bank, pp 109, 126-128

Murty JVR, Agarwal S, Shah P (2007) Maharashtra, India: improving panchayat service delivery through community score cards. Social accountability series. Available at http://www.sasanet.org/ curriculum_final/downlaods/SM/Working\%20Papers\%20\&\%20Case\%20Studies/SM\%20CS1.pdf

Pande S (2008) The right to information and societal accountability: the case of the Delhi PDS campaign. IDS Bull 38:52

Pandey P, Goyal S, Sundararaman V (2009) Community participation in public schools: the impact of information campaigns in three Indian states. Educ Econ 17:355

Pandey P, Sehal AR, Riboud M et al (2007) Information resource-poor populations and the delivery of entitled health and social services in rural India: a cluster randomized controlled trial. J Am Med Assoc 298:1867

Pritchett L, Sandefur J (2014) Context matters for size: why external validity claims and development practice do not mix. J Glob Dev 4:161

Ramanujam N, Anstis S (2013) Legal empowerment, social movements and fostering equitable economic development in Cambodia. Can J Poverty L 2:104-139

Ravallion M (2009) Should the randomistas rule? Econ Voice 6:1-5

Ravindra A (2004) An assessment of the impact of Bangalore citizen report cards on the performance of public agencies. ECD Working Paper Series 12, World Bank Operations Evaluation Department

Reinikka R, Svensson J (2005) Fighting corruption to improve schooling: evidence from a newspaper campaign in Uganda. J Eur Econ Assoc 3(259):260

Ringold D et al (2012) Citizens and service delivery: assessing the use of social accountability approaches in human development. The World Bank

Rondon PAM (2015) Association of rule of law and health outcomes: an ecological study. BMJ Open 5(10):1-9 
Roselyn N, Kareithi M, Lund C (2012) Review of NGO performance research published in academic journals between 1996 and 2008. S Afr J Sci 108(1):5

Sandefur J, Siddiqi B (2013) Delivering justice to the poor: theory and experimental evidence from liberia. Available at https://editorialexpress.com/cgi-bin/conference/download.cgi?db_name= CSAE2013\&paper_id=1014

Sheldrick BM (2012) Access to justice and legal empowerment as vehicles of poverty alleviation: good governance challenges to linking legal structures to social change. Centre For Int'l Sustainable Dev. Law. Available at http://www.cisdl.org/public/docs/Sheldrick_Access_to_Justice_and_Legal_ Empowerment.pdf

Singh P, Sachs JD (2013) 1 million community health workers in sub-Saharan Africa by 2015. The Lancet, March 29

Song F, Hooper L, Loke YK (2013) Publication bias: what is it? how do we measure it? How do we avoid it? Open Access J Clin Trials 5:71-73

Stephens M (2009) The commission on legal empowerment of the poor: an opportunity missed. Hague J Rule Law 1(132): 140

Thornton A, Lee P (2000) Publication bias in meta-analysis: its causes and consequences. J Clin Epidemiol 53(207):208-209

Trubek DM, Galanter M (1974) Scholars in self-estrangement: some reflections on the crisis in law and development studies in the United States. Wis L Rev 1062:1070-1072

UN Secretary-General (2014) The road to dignity by 2030: ending poverty, transforming all lives and protecting the planet: synthesis report of the Secretary-General on the post-2015 sustainable development agenda. UN Doc A/69/700, §78

UNICEF (2010) Birth Registration in Bangladesh. http://www.unicef.org/bangladesh/Birth_ Registration(1).pdf

van Rooij B (2012) Bringing justice to the poor, bottom-up legal development cooperation. Hague J Rule L 4(286):308-309

Waldorf L (2015) Introduction: legal empowerment in transitions. Int J Hum Rights 19:229

Wiggan J, Talbot C (2006) The benefits of welfare rights advice: a review of the literature. National Association of Welfare Rights Advisors. http://nawra.org.uk/Documents/Benefitsofwelfarerightsadvicelitreview.pdf

Wojkowska E, Cunningham J (2010) Justice reform's new frontier: engaging with customary systems to legally empower the poor. In: Golub S (ed) Legal empowerment: practitioners' perspectives, pp 93, 108

Woolcock M, Szreter S, Rao V (2011) How and why does history matter for development policy. J Dev Stud 47:70

World Bank (2011) World Bank Directions in Justice Reform. Available at http://siteresources. worldbank.org/EXTLAWJUSTINST/Resources/wb_jr_discussionnote.pdf 